\title{
Pre-service Teachers' Belief Change and Practical Knowledge Development during the Course of Practicum
}

\author{
Emre Debreli \\ Correspondence: Emre Debreli, Faculty of Education, European University of Lefke, Gemikonagi, Cyprus via Mersin 10 \\ Turkey.
}

\author{
Received: March 22, 2016 Accepted: March 29, 2016 Online Published: April 1, 2016 \\ doi:10.11114/jets.v4i7.1513 URL: http://dx.doi.org/10.11114/jets.v4i7.1513
}

\begin{abstract}
This study deals with the nature of change processes that pre-service teachers undergo throughout their training in an English Language Teaching programme. It also explores the types of beliefs about learning and teaching that pre-service teachers held before starting the practical phase of the programme and whether and how the practical phase changed their beliefs in nine-month period. Participants included 12 pre-service teachers at a university in Northern Cyprus. Data were collected through semi-structured interviews in three different phases: at the beginning, during and at the end of the training programme. Diaries were also used on a regular basis. The study found that when the participants started the training programme, they held numerous beliefs about learning and teaching-many based on theoretical rather than practical knowledge. An analysis of the data obtained in the latter phases indicated that all the participants underwent changes in the various beliefs they initially held. Furthermore, the participants faced many difficulties when their theoretically derived beliefs were confronted with the reality of practice, which, in several instances, led to changes in beliefs and the development of practical knowledge.
\end{abstract}

Keywords: beliefs, pre-service teachers, practical knowledge, teaching training, practicum

\section{Introduction}

Research on teachers' beliefs has emerged in the last 20 years as an important area of inquiry in the field of language teaching. One strand of this work has primarily focused on pre-service language teachers, and there has been interest primarily in the changes that occur in pre-service language teachers' beliefs about learning and teaching throughout teacher education. A popular conviction exists that pre-service teachers approach teacher training programs with unrealistic or inappropriate beliefs (Borg, 2006) that need to be altered; thus, it is crucial to explore the processes they undergo throughout their training with regard to their belief change. Although a number of studies have provided pessimistic conclusions about this phenomenon (i.e. Fajet, Bello, Leftwich, Mesler, and Shaver, 2005; Joram and Gabriele, 1998; Peacock, 2001), a considerable number (i.e. Cabaroglu and Roberts, 2000; Lihua, 2010; Ng, Nicholas, and Williams, 2010) express optimism. One reason why these findings differ, or perhaps are interpreted differently, might be that, often, little information is available about the teacher education programmes being offered), which makes it difficult to generalise the existing findings. Nearly two decades ago, Bramald, Hardman, and Leat (1995) drew attention to the matter of teacher education programmes being mostly regarded as a constant rather than as a variable. The constantvariable relationship here refers to teacher belief studies that often do not take the nature and quality of teacher education programmes into consideration and rather focus solely on teachers' belief change. This criticism appears to have regained importance in recent years, and as Zheng $(2012,3)$ suggested, researchers have now come to realise that in 'any research on educational issues, it is necessary to examine the educational context in which the study is undertaken when investigating any educational beliefs or teachers' beliefs'. Another reason why research on pre-service teachers' belief change remains inconclusive might be linked to Borg's (2006) assertion that we know only a little about how, rather than whether, pre-service language teachers' beliefs change throughout teacher education and that such a lack of understanding is likely to weaken researchers' interpretation of what the change actually is. According to Borg (2006), research into such aspects deserves singular priority.

The present study focuses on EFL pre-service teachers' belief change (whether they change and how they change) throughout their nine-month training during the practicum phase of the English Language Teaching (ELT) programme at a university in Northern Cyprus. To evaluate belief change and its nature, Cabaroglu and Robert's (2000: 395) belief 
change framework is adopted. The present study contributes to the field by identifying a teacher education-belief correlation as well as providing a detailed picture of pre-service teachers' belief development.

\subsection{Teachers' Beliefs and Knowledge}

In the area of teacher education, Richardson (1997: 103) defined the concept of belief as 'psychologically held understandings, premises and propositions about the world that are held to be true'. In other words, what a pre-service teacher believes and perceives to be the facts is considered to be his/her belief. However, a common problem in studying teachers' beliefs is confusing the construct 'belief' with the construct 'knowledge'. Both constructs are often said to be epistemologically different - belief is based on evaluation and judgment and is subjective, whereas knowledge is based on the condition of truth and is objective (Woolfolk-Hoy, Davis, and Pape, 2006). In other words, the term knowledge can be used to refer to things we know, 'conventionally accepted facts' (Woods, 1996: 195) or something that has been demonstrated or is demonstrable, whereas the term belief can be used to refer to the acceptance of a proposition for which 'there is no conventional knowledge and one that is not demonstrable' (Woods, 1996: 195). The term 'knowledge', in the literature of teacher education, is classified in various forms (e.g. pedagogical content knowledge, practical knowledge, declarative and procedural knowledge) and is discussed in isolation from the beliefs teachers hold. Although this study uses the term belief inclusively as an umbrella term that may also include knowledge, it is important to acknowledge that there are instances in which knowledge cannot be conceptualised as a part of teachers' beliefs.

\subsection{Pre-service Language Teachers' Beliefs about Learning and Teaching}

To date, pre-service language teachers have been noted to hold various types of beliefs when they start their teacher training, which act as filters to the input provided during their training and are difficult to change. Some of these beliefs are often categorised as language aptitude (Altan, 2006); motivation and willingness to learn the target language (Tercanlioglu, 2005); learning and memorising vocabulary and grammar rules; use of materials; teaching techniques; classroom management; error correction; teacher roles (Altan, 2006; Mattehoudakis, 2007; Wong, 2010) and so forth. These beliefs are derived from pre-service teachers' previous learning experiences (positively or negatively) as students (Busch, 2010), teacher education (Da Silva, 2005), experience of teaching, personality factors, educational principles, principles derived from an approach or method (Richards and Lockhart, 1996) and so on. Some studies, however, have shown that certain beliefs that pre-service language teachers brought to training programmes were inappropriate or tended to be unrealistic when evaluated according to today's language teaching norms (Altan, 2006; Mattheoudakis, 2007; Peacock, 2001). In Altan's (2006) study, for example, 85\% of the pre-service teachers at the beginning of their training mentioned that foreign language learning is mostly a matter of vocabulary and grammar learning, which, based on current approved norms of language teaching and learning, is not acceptable. Similar findings were also observed in Peacock's (2001) study. This is perhaps why research on pre-service language teachers' belief change has gained significance, as a way of understanding whether pre-service language teachers' inappropriate or unrealistic beliefs can be altered when they enter teacher education programmes.

\subsection{Setting of the Study}

The study was carried out with a group of Turkish ELT pre-service teachers at a university in Northern Cyprus. One of the main aims of the ELT programs run by universities there is to educate and prepare teacher candidates for teaching at the secondary level. The programs are taught over four years, with each year divided into two terms. The figure provided in Appendix A presents the modules in each term and year in the ELT programme that this study examined, but the appendix can also be viewed as a representative dynamic for each of the ELT programmes run by universities in Northern Cyprus.

In these modules, the instructors follow the material in published textbooks chapter by chapter, focusing on important points through discussions. Generally, peer or group discussions on the issues covered take place at the conclusion of each lesson. Once or twice during the term, in non-assessed sessions, students are given case studies to help them comment and critically reflect on what they have learned from the modules or are encouraged to participate in discussions and thereby build new understanding. Students are not usually encouraged to take part in any activities apart from these. As the system is exam based, students demonstrate their knowledge in the examinations. Only in the module Teaching Language Skills II are pre-service teachers required to design lesson plans and take part in a microteaching activity, which lasts for only 15 minutes. They then prepare a teaching task and deliver it to their classmates. These are the only activities that are used to promote reflective thinking and teaching, and the microteaching session is the only practical opportunity for pre-service teachers until they start the final year of the programme.

\subsubsection{Pre-service Teacher Training Programme}

In the last year of the ELT programme, which is a practice-based year, two modules-'School Observation' and 'Teaching Practice'- play a crucial role in facilitating pre-service teachers' practical experience. These modules carry 
more weight than the others and constitute the 'teacher training programme' discussed throughout this paper.

The main purpose of the School Observation module, taken in the first term, is to provide pre-service teachers with opportunities that will help them develop reflective thinking related to various teaching- and learning-related issues. In the first weeks of the module, they review what they learned in the previous year's methodology modules. Then, pre-service teachers are sent to different middle or high schools to observe teachers and learners in context for six hours in total. Those who become successful in this course have the opportunity to continue with the Teaching Practice module in the following term. Teaching Practice, taken in the second term, is the most substantial component of the ELT programme. When pre-service teachers begin this module, they continue to attend review sessions (lessons) within the department and spend most of their time designing and preparing lesson plans. After the first month of the module, pre-service teachers are again sent to middle and high schools, where they are required to teach at least four lessons (50 minutes each) during the rest of the term. During these class sessions, pre-service teachers are observed by the actual teacher of the classroom in which they teach, and that teacher informs their supervisors about their performance. After completing each lesson, pre-service teachers meet with their supervisors and discuss issues regarding their teaching experience.

\section{Method}

The present study adopted a qualitative research design with the intention of exploring the phenomenon in depth over a period of time (Bryman, 2008).

\subsection{Research Questions}

This qualitative study focuses on the following three research questions of the several questions addressed in the larger study:

- What type of beliefs do pre-service teachers have about learning and teaching EFL at the beginning of the practical phase of the pre-service teacher training programme?

- To what extent does practical teaching bring about a change in pre-service teachers' beliefs?

- How does a change in pre-service teachers' beliefs occur?

\subsection{Participants}

Participants were a randomly selected volunteer sample of 12 Turkish EFL pre-service teachers (five male and seven female, with an age average of 21 years) who were studying in their final year of an ELT programme. None of these pre-service teachers had any prior teaching experience. In the fall semester of the present teacher training programme, they had completed their required six hours of observation sessions. In the spring semester, apart from two individuals who had practiced teaching for only three hours due to conflicts, the rest of the group had completed the required four hours.

\subsection{Data Collection and Analyses}

This study adopted a qualitative research design and explored teachers' belief change over a period of nine months using semi-structured interviews and diaries. During the nine-month period, three one-to-one interviews of approximately 45 minutes each were conducted at approximately four-month intervals (before, during and after the training programme) with each pre-service teacher. Within a planned framework of themes, semi-structured interviews (Kvale, 2007) were used to explore themes as they arose. One of the main reasons for using such a conversational tool is the conviction that 'beliefs elicited through the discussion of actual classroom practices may be more rooted in reality - beliefs about what is - and reflect teachers' practical or experiential knowledge' (Phipps and Borg, 2009: 382). Teachers were asked a flexible set of questions from a list in the first phase of the data collection to initiate the process. Follow-up questions were also extensively used to explore their beliefs in more depth, depending on the responses given by participants. Primarily, open questions were used in order to allow the participants to explain their thoughts freely. A similar strategy was also used in the second and third phases of the interviews, and they were given opportunities to comment on the transcriptions of the previous interviews (i.e. whether they wanted to change anything).

All of the interviews conducted in each phase were audio recorded and transcribed verbatim. The interview data obtained from all phases were coded and categorised according to the themes that emerged from the data, with the best care taken to avoid either imposing prior categories of analysis or pre-developing such categories. To avoid this, two other researchers also provided help by coding and categorising the data (Bryman, 2008), and an agreed-upon set of codes and categories was developed throughout this process. When analysing the interview data, only the first phase was analysed separately from the others, as the aim was to identify a set of beliefs that would be tracked for changes in the second and third phases. The data from the other phases were analysed with a focus on the changes that appeared in 
beliefs that had been identified in the first phase. The whole process of interview data analysis, which can be described as cyclical rather than linear, involved going back and forth in the data and repeating the same or similar procedures where necessary.

A contemporaneous diary writing activity was also used with the intention of eliciting more extensive and detailed data (i.e. participants' reflective writing — revealing beliefs and specific examples attached to those beliefs-which can provide insights that might otherwise remain hidden during oral interaction). The diary technique also helps determine the participants' hidden affective factors and language learning experiences in order to explore specific experiences and their feelings and to reveal how and why those feelings were integrated and associated with those experiences. Throughout the nine-month training period, teachers were asked to submit a diary at approximately one-month intervals explaining the critical incidents that occurred in any of the classes they observed/taught and how they felt, what they learnt and what they would have done differently.

The analyses of the diary data were similar to the interview data. The process involved coding and categorising data by consistently going back and forth in the data. Several cross-checks between the diary and the interview data were also conducted to develop a broader understanding of the teachers' cognition.

\section{Findings}

\subsection{Initial Beliefs about Learning and Teaching}

This section provides some of the belief categories that initially emerged in the larger study, which are shown in Table 1, in Appendix C. In the main study, the categories of the language aptitude, role of activities and error correction and the importance of input, output, interaction, communication (subcategorised under teaching approach) and classroom management also appeared. Because the main focus is on the process of change, these initial beliefs are given to serve as a guide in better understanding the latter sections of this paper, as well as to reveal specific belief types that emerged from this specific context. Relevant examples that are representative of the overall cohort are also indicated in the table.

Table 1. Pre-service teachers' initial beliefs about learning and teaching

\begin{tabular}{ll}
\hline Category & Example data \\
\hline $\begin{array}{l}\text { Teaching Approach } \\
\text { Explicit vs. implicit teaching of grammar }\end{array}$ & $\begin{array}{l}\text { 'Teaching should mainly focus on meaning rather than } \\
\text { form', 'students should learn in context', 'form-focused } \\
\text { teaching equals to parrot learning'. } \\
\text { 'I believe teachers should be facilitators in the } \\
\text { classroom', 'teacher should possess a prompter role', } \\
\text { 'teachers should adopt an authoritarian role'. }\end{array}$
\end{tabular}

Teacher characteristics

- Affective attributes

- Cognitive attributes

$\circ \quad$ Knowledge of theory

$\circ \quad$ Knowledge of practice
'Good teachers should have a good rapport with the students', 'teachers should be caring and patient'.

'Teachers should have a rich knowledge of language teaching theories and methods'.

'Teachers should employ their theoretical knowledge in practice successfully'.

In almost all of the categories given in Table 1, pre-service teachers seemed to have naive understandings of teaching and learning, both from a theoretical and a practical perspective. The data reflects that they often made simple choices about the beliefs they held (e.g. they believed that speaking and listening were the most important skills, whereas other skills were not important at all; the facilitator was the most important teacher role, whereas the other roles were not). As senior students of the ELT programme, however, it was anticipated that they would understand that all skills and components of a language, for example, are important, with some possibly deserving less attention, rather than simply believing that some of them deserved no attention at all. Moreover, they were expected to be aware that teachers adopt many roles in the classroom when necessary, rather than believe that one role was the best and the others useless. Their simplistic understanding is perhaps due to their inexperience and lack of exposure to practice and indicates a clear lack of procedural knowledge.

\subsection{Change in Pre-service Teachers' Beliefs about Learning and Teaching after Exposure to Practice}

In order to explore the nature of pre-service teachers' belief change, Cabaroglu and Robert's (2000: 395) framework on the nature of belief change/development is employed (see Appendix B for the framework). The framework demonstrated the extent to which the beliefs held by pre-service teachers when they started the training programmme 
changed during the practical phase of the programme, as well as how they changed —emphasising how the beliefs were confronted by the reality of practice.

\subsubsection{Teaching approach: Explicit Versus Implicit Teaching of Grammar}

Many of the pre-service teachers who initially expressed preferences about adopting implicit teaching approaches seemed to experience 'confirmation' and a 'strengthening' of their beliefs. William, for example, wrote the following in one of his diary entries after observing a lesson:

She [the teacher] usually encouraged students to infer meanings themselves ... I think the ways how the teacher encouraged students to infer meanings from the context was an effective way of learning and teaching because she activated their critical thinking skills ... It has been good to see how a teacher teaches by focusing on meaning and what kinds of examples she gives when doing this. I feel more confident with my approach to teaching now. William, Diary 2

It seems that William witnessed how his initial belief worked in the classroom he observed, and this allowed him to be more certain about what he believed, which can be regarded as confirmation of his existing belief.

Ruth, in contrast, seemed to complete the training programme with different ideas. Although during the initial interviews, she criticised teachers who adopt explicit teaching techniques, these ideas seemed to be reshaped by the end of her training. In the final interview, Ruth said,

I think focusing on meaning too much does not work so well with the students whose level of proficiency is low, and with these students, you need to be more explicit ... Yes, but I am not like that anymore because I experienced it ... Because that [consistent use of implicit approaches] can cause incorrect acquisition of the topics taught ... I think the best thing to do is to describe the rules step by step and then continue by providing examples and encouraging them to guess themselves ... No, I agree with what I said, but I am more flexible now. Ruth, Int. 3

The above excerpt seems to be rich in terms of the change processes appearing in the teacher's beliefs, as there are patterns of 'realisation', 'addition' and a 'reordering'. Ruth experienced a negative occasion when using implicit approaches, and her students could not follow her efficiently owing to their level of language proficiency. As a result, she came to realise a discrepancy in her initial belief. This understanding seems to lead her to search for an alternative, more comprehensible teaching method, and thus, she ideates using explicit teaching approaches in addition to implicit ones, which can be considered as an addition of a new belief to her repertoire. The addition of new beliefs to her repertoire also seems to proceed with reordering, as a result of the realisation of the need for flexibility. She may have fallen back on the approaches she had experienced as a learner when the new approach did not seem to work. Her own lack of skill, rather than just the pupils' low proficiency level, could also be an explanation for why the teaching did not go well. She may be reacting to this 'failure' by resorting to what she knew very well, that is, her own learning experience.

\subsubsection{Teacher Roles}

The conception of preferring one role over others did not seem to change much in the phases of the training programme that followed, as most of the pre-service teachers seemed to continue discussing teacher roles either by comparing one role to another or by disagreeing with the initial role they preferred and heading towards another single role. Only a few seemed to realise the importance of adopting multiple roles throughout their training.

Among the pre-service teachers who initially brought up the importance of teacher roles as prompter and facilitator, William, Marilyn, Margaret and Edward later suggested the teacher as controller role as being important. It seemed that these pre-service teachers developed this idea as a result of various difficulties they faced in classrooms in which the students misbehaved, and they realised the importance of exerting control over students when teaching. Marilyn, for example, expressed this issue in her final interview (along with Margaret, Edward and William), saying,

I still agree with the importance of facilitator role, but I think controlling the students during the lessons is the most important thing to do ... Because if you cannot control them, you cannot facilitate the learning process. Students are likely to misbehave anytime, so they should be controlled first. Marilyn, Int. 3

The main issue in the above excerpt is that Marilyn's belief that the teacher's role should be as a facilitator did not disappear, but it seems that the role of controller gained more importance. Although we do not know whether this was a new belief that was added to her repertoire (because she did not cite such a role at the beginning of the study), it is clear that she became aware of the importance of the controller role either by adding it to her repertoire or by strengthening it, 
and she then reordered her beliefs with regard to their importance. Marilyn's above comment becomes clearer through one of her diary entries:

The students were too active, and I couldn't control them. Although I warned them several times, they didn't stop and I was panicked ... Although my aim was to establish a student-centred classroom, this didn't work. My aim was not to interrupt students during the activities so that they could have interacted freely. But I learned that giving them such freedom and establishing fully student-centred classrooms was not a good idea ... I would definitely exert more control over the students rather than allowing them to be active members during the lesson. Marilyn, Diary 3

Marilyn's comments above imply that she resorted to a more traditional approach when her lack of skill/adaptability left her clueless. She interprets the role she adopted as 'not a good idea', rather than identifying the way in which she set up the activity as the problem.

Paul, in contrast, seemed to experience a pseudochange in his beliefs. Initially, he cited the role of teacher as controller as being the most important and the one he would prefer to adopt when teaching. His comments during the final interview, however, indicate a conflict between what he believed and 'what his supervisor expected' him to do when he went into the classroom. Paul said that he did not assume a controller role in the lessons he taught 'in order not to be criticised' by his supervisor. This could be regarded as a pseudochange, that is, he adopted feigned practices.

\subsubsection{Teacher Characteristics: Affective Attributes}

At the beginning of the study, pre-service teachers mainly described effective/good teachers from an emotional perspective and mentioned various characteristics that made a teacher effective/good. Later, only a few seemed to add new beliefs to their repertoire and disagreed with some of the issues they had previously mentioned.

At the end of the study, Albert, Laura, Dominick, Ruth and Charlotte agreed with what they had initially said, without adding anything new or further discussing their earlier ideas. This might be regarded either as confirmation or no change in their beliefs.

The beliefs of Paul, William, Margaret, Melissa and Edward, however, seemed to be elaborated/polished by the addition of new beliefs to their repertoire. Comments by these pre-service teachers showed that they became more aware of the interpersonal characteristics that can make a teacher effective after observing various teachers and completing a number of teaching sessions. Paul, for example, who initially viewed the most important effective teacher characteristic as being patient, seemed to develop his conception at the end of the study by conceptualising other characteristics, such as 'being enthusiastic', 'liking the job' and 'being confident'. This is surely a development in his beliefs and can be regarded as an elaboration/polishing of his beliefs by reconstructing them through adding new beliefs. It is difficult to assert, however, that Paul did not have these ideas at the beginning. The issue here is that even if he was aware of these perspectives, these beliefs gained more importance only after his observations in the training programme and after seeing that such characteristics made teachers more effective.

\subsubsection{Teacher Characteristics: Cognitive Attributes}

The data gathered in the following phases of the study showed that the practical application of theory gained more importance. During the initial analysis, these two sub-categories were discussed separately, as they were clearly distinct. In the following section, however, these two sub-categories were combined and discussed as a single sub-category, namely 'theory and practice'. Because the pre-service teachers seemed to create links between knowledge of theory and of practice in the later phases of the study and provided data where the issues of theory and practice relationship were intertwined, it was believed that the exploration of such data under a single category would better illustrate this relationship and development in their beliefs.

\subsubsection{Theory and Practice}

Among the pre-service teachers who initially viewed having a rich knowledge of language teaching theories and methods as one of the characteristics of effective/good teachers, many seemed to experience various awareness/realisation processes in their beliefs. When asked in the final interview whether she agreed with what she had said earlier about the characteristics of the effective/good teacher, for example, Melissa expressed herself in a very uncertain way (echoing the majority):

I still agree with these but I realised that being effective is not only about these ... Whenever I teach in classrooms, I feel like there is something missing. I've got good relationships with the students, they like me and they usually participate in my lessons, but when I teach them something, they sometimes don't understand and I feel very bad at those times because I try to recall another way of teaching, and it sometimes does not come up. I mean, although I know what to do theoretically, the difficulty is to recall 
them at that time. It's difficult to describe. I think I need to develop myself because that is the difficulty I usually face, and it affects my teaching quality. Melissa Int. 3

The above extract demonstrates the clear awareness of a discrepancy that seems to be having a negative impact on Melissa's teaching. She noticed that the affective attributes she had prioritised at the beginning of the study were not sufficient to enable her to teach successfully. She also became aware that knowing how to teach a language was not enough either, as the most important issue to her now seemed to be on the practical side of teaching, that is, how to convey what she knew to the students. It seems that she experienced a lack of competence in practice, as she acknowledges that although she knew what to do on a theoretical basis; she faced difficulties in applying this in practice. As a result, she seems to elaborate/polish her initial beliefs by adding the idea of the need to develop such knowledge of practice, and she seems to link it to experience.

\section{Discussion and Conclusion}

\subsection{Pre-service Teachers' Initial Beliefs}

The initial data revealed that pre-service teachers bring a variety of beliefs concerning learning and teaching to the programme, which they were clear and confident about. However, their reasons for holding those beliefs indicated a lack of practical knowledge, of which they were not yet aware. The present study suggests that EFL pre-service teachers start the training programme with strong beliefs that can be called non-traditional, or beliefs that reflect the characteristics of communicative approaches, as compared with some of the existing studies (e.g. Altan, 2006; Tercanlioglu, 2005), which report the opposite.

In terms of motivation, teacher characteristics and teacher roles, some other conflicting beliefs appear. The majority of the pre-service teachers seemed to naively believe that motivated students are more successful, which contradicts Dörnyei's (2001) study, which defined motivation as the 'antecedent of action rather than achievement' (198). Findings concerning the theme of teacher characteristics are also rather naive and indicated pre-service teachers' lack of practical awareness/knowledge. Most of the pre-service teachers believed that affective attributes, such as developing good relationships with the students, being understanding, liking the job and being patient, were crucially important in making a teacher effective, as reported in the study by $\mathrm{Ng}$ et al. (2010). However, few believed that cognitive attributes, such as a rich repertoire of language-teaching theories, made a teacher effective, and fewer viewed practical application of theoretical knowledge as a characteristic that makes a teacher effective, which again indicates their limited awareness of practical issues. This limitation is perhaps due to a failure to consider the actual mental processes of teachers or the tendency to evaluate the teacher according to their own emotional concerns (e.g. how they themselves wanted to be treated by their teachers). The pre-service teachers' beliefs concerning the teacher roles they would adopt also seemed to move away from the ideal conception that exists in the literature and reflected their limited awareness of classroom practice. The initial data also suggest that pre-service teachers often made simple choices about the teacher roles they viewed as effective and preferred to adopt, and when, for example, they viewed one role as effective, they tended to view the others as less important.

\subsection{Beliefs after Practice Teaching}

During their teaching practice, all of the pre-service teachers seemed to experience changes in the various beliefs they had initially held. These changes, however, occurred in different ways and to differing degrees. These findings contradict the findings in similar EFL contexts (e.g. Altan, 2006; Mattheoudakis, 2007; Peacock, 2001; Tercanlioglu, 2005), whereas they are in agreement with the majority of the studies conducted in ESL and L1 contexts (e.g. Mansfield and Volet, 2010; Ng et al., 2010).

When pre-service teachers attempted to apply their initial beliefs in practice, they sometimes exhibited a lack of skill and flexibility in adapting the technique or approach to a given context and to the many complexities that exist in classrooms. An underdeveloped teaching repertoire also seems to have caused pre-service teachers difficulties in circumstances in which they could not apply their preferred approach/principle in practice and when they found themselves searching for alternative approaches/principles.

In the present study, a key theme that emerges is that pre-service teachers are confronted with the realisation of the difficulty in practising the beliefs they hold, especially those informed by theory. As a result, some seem to start believing that the approaches and techniques based on these beliefs are not effective or are more difficult to adopt than they initially thought and that flexibility is needed in adapting teaching approaches to the classroom context. Some then turn to more traditional and familiar approaches, perhaps those that come from their own experience of language learning. Others are better able to modify their teaching approaches, rather than rejecting their existing beliefs. For those who see the need for flexibility and modification, such challenges may allow them to think more critically and become aware of their lack of practical knowledge. As a result, their conceptions of language teaching and learning 
become less naive. They also seem to start modifying their initial black-and-white views and thinking more flexibly. For example, rather than making simple choices about the teaching approaches, they seem to become more aware of the validity of each approach when teaching, which may show their thinking becoming more pragmatic, instead of dogmatic. Such experiences may indicate how right Korthagen (2010) was in arguing that theory, in its current form, tends to remain irrelevant to practice: theory and practice are separate entities in the present ELT programme or there exists an imbalanced gap between theory and practice, whereas such conflicts could be mitigated by offering a more balanced exposure to theory and practice.

\subsection{Nature of Change in Beliefs}

The present study suggests that the concept of 'change' is broader and more complicated than that presented in the majority of existing studies (Altan, 2006; Peacock, 2001; Tercanlioglu, 2005). Much of the data address that pre-service teachers in the present study often experience many of the change processes as suggested in Cabaroglu and Robert's (2000) framework. Some teachers, for example, realise the difficulty of implementing certain approaches in the classroom, but instead of removing these beliefs from their repertoire, they elaborate/polish them. Alternatively, when they realise that their initially held beliefs work successfully in practice, these beliefs become confirmed and stronger, indicating a development/change in beliefs. On some occasions, they also add new beliefs to their repertoire and reorder their initially held beliefs with the new beliefs. Patterns of pseudochange are another prominent theme in the present study. Although the pre-service teachers still had naive understandings of some issues, and some of them continued to hold 'either-or' beliefs, the overall data suggest a kind of movement in their general conception of language teaching and learning, which may be an indicator of further development in beliefs when the teachers are given more practical opportunities.

\section{Implications and Limitations}

The difficulties these pre-service teachers experienced when they entered the classroom may guide teachers and programme and curriculum designers in designing or modifying the training programmes and the curriculum. It can be inferred from the present context that years of heavy emphasis on theories of language teaching and learning seem to have influenced pre-service teachers' beliefs throughout the course of the present ELT programme. In addition, late and limited exposure to practice teaching can be viewed as a factor that inhibits pre-service teachers from developing pedagogical reasoning in the earlier years of the ELT programme, and resulting in various difficulties and conflicts when they start their practice teaching. Earlier exposure to practice might have lessened the difficulties and conflicts pre-service teachers experienced throughout the programme. It is questionable whether the pre-service teachers in the present study found ample opportunities to apply their past theoretical knowledge into practice owing to the limited hours of practice teaching. This is not to say that their beliefs would not change if they had had more practice teaching sessions, had been exposed to practice earlier or had been exposed to more activities to promote reflective thinking and pedagogical reasoning. However, they would possibly have had greater awareness of the complexities and difficulties that exist in practice, and thus, they would have had an idea of the difficulties and conflicts awaiting them. Another suggestion is that pre-service teachers need more practice teaching sessions, as this can help them develop more practical awareness.

This study was based on qualitative data from a relatively small number of pre-service teachers, and thus, they represent only a specific programme that has been considered. The chosen methods for data collection, although relevant for studies of this kind (Borg, 2006), might be viewed as limited in terms of not offering any observational aspect undertaken by the researcher, which would enrich the findings of the study. However, the institution did not permit the undertaking of observations. Such data would probably have resulted in richer and perhaps different results.

\section{References}

Altan, M. Z. (2006). Beliefs about language learning of foreign language-major university students. Australian Journal of Teacher Education, 31(2), 45-52. http://dx.doi.org/10.14221/ajte.2006v31n2.5

Borg, S. (2006). Teacher cognition and language education. London, UK: Continuum.

Bramald, R., Hardman, F., \& Leat, D. (1995). Initial teacher trainees and their views of teaching and learning. Teaching and Teacher Education, 11(1), 23-31. http://dx.doi.org/10.1016/0742-051x(94)e0009-t

Bryman, A. (2008). Social research methods $\left(3^{\text {rd }}\right.$ ed). Oxford, UK: Oxford University Press.

Busch, D. (2010). Pre-service teacher beliefs about language learning: The second language acquisition course as an agent for change. Language Teaching Research, 14(3), 318-337. http://dx.doi.org/10.1177/1362168810365239

Cabaroglu, N., \& Roberts, J. (2000). Development in student teachers' pre-existing beliefs during a 1-year PGCE programme. System, 28(3), 387-402. http://dx.doi.org/10.1016/s0346-251x(00)00019-1 
Da Silva, M. (2005). Constructing the teaching process from inside out: How pre-service teachers make sense of their perceptions of the teaching of the four skills. TESL-EJ, 9(2), 1-9.

Dörnyei, Z. (2001). Attitudes, orientations, and motivations in language learning. Maldon, MA: Blackwell Publishing.

Fajet, W., Bello, M., Leftwich, A. S., Mesler, L. J., \& Shaver, N. A. (2005). Pre-service teachers' perceptions in beginner education classes. Teaching and Teacher Education, 21(6), 623-637. http://dx.doi.org/10.1016/j.tate.2005.05.002

Joram, E., \& Gabriele, A. J. (1998). Preservice teachers' prior beliefs: Transforming obstacles into opportunities. Teaching and Teacher Education, 14(2), 175-191. http://dx.doi.org/10.1016/s0742-051x(97)00035-8

Kvale, S. (2007). Doing interviews. London, UK: Sage Publications.

Lihua, Y. (2010). A study of ethnic Mongolian university EFL teachers' beliefs and decision making. Chinese Journal of Applied Linguistics, 33(2), 60-75.

Mansfield, C. F., \& Volet, S. E. (2010). Developing beliefs about classroom motivation: Journeys of preservice teachers. Teaching and Teacher Education, 26(7), 1404-1415. http://dx.doi.org/10.1016/j.tate.2010.04.005

Mattheoudakis, M. (2007). Tracking changes in pre-service EFL teacher beliefs in Greece: A longitudinal study. Teaching and Teacher Education, 23(8), 1272-1288. http://dx.doi.org/10.1016/j.tate.2006.06.001

Ng, W., Nicholas, H., \& Williams, A. (2010). School experience influences on pre-service teachers' evolving beliefs about effective teaching. Teaching and Teacher Education, 26(2), 278-289. http://dx.doi.org/10.1016/j.tate.2009.03.010

Peacock, M. (2001). Pre-service ESL teachers' beliefs about second language learning: A longitudinal study. System, 29(2), 177-195. http://dx.doi.org/10.1016/S0346-251X(01)00010-0

Phipps, S., \& Borg, S. (2009). Exploring tensions between teachers' grammar teaching beliefs and practices. System, 37(3), 380-390. http://dx.doi.org/10.1016/j.system.2009.03.002

Richards, J. C., \& Lockhart, C. (1996). Reflective teaching in second language classrooms. Cambridge, UK: Cambridge University Press.

Richardson, V. (1997). Constructivist teacher education: Building a world of new understandings. London, UK: Falmer Press.

Tercanlioglu, L. (2005). Pre-service EFL teachers' beliefs about foreign language learning and how they relate to gender. Electronic Journal of Research in Educational Psychology, 5(1), 145-162.

Wong, M. S. L. (2010). Beliefs about language learning: A study of Malaysian pre-service teachers. RELC Journal, 41, 123-136. http://dx.doi.org/10.1177/0033688210373124

Woods, D. (1996). Teacher cognition in language teaching beliefs, decision-making, and classroom practice. Cambridge, UK: Cambridge University Press.

Woolfolk-Hoy, A., Davis, H., \& Pape, J. S. (2006). Teacher knowledge and beliefs. In P. A. Alexander \& P. H. Winne (Eds.), Handbook of Educational Psychology (pp. 715-737). New York, NY: Routledge.

Zheng, H. (2012). Dilemmas in teacher development in the Chinese EFL context. Journal of Cambridge Studies, 7(2), $2-16$. 


\section{Appendix A}

Modules taken in the ELT programme

\begin{tabular}{|c|c|c|}
\hline & $1^{\text {st }}$ term & $2^{\text {nd }}$ term \\
\hline \multirow{5}{*}{$1^{\text {st }}$ year } & Contextual Grammar I, Advanced Reading and & Contextual Grammar II, Advanced Reading and \\
\hline & Writing I, Listening and Pronunciation I, Oral & Writing II, Listening and Pronunciation II, Oral \\
\hline & Communication Skills I, Introduction to & Communication Skills II, Vocabulary and \\
\hline & Educational Sciences, Turkish, Computer I & Educational Psychology, Effective \\
\hline & & Communication Skills, Computer II \\
\hline \multirow{3}{*}{$2^{\text {nd }}$ year } & $\begin{array}{l}\text { English Literature I, Linguistics I, Approaches } \\
\text { to ELT I. English-Turkish Translation. }\end{array}$ & $\begin{array}{l}\text { English Literature II, Linguistics II, Approaches } \\
\text { to ELT II. Turkish-English Translation. }\end{array}$ \\
\hline & $\begin{array}{c}\text { Principles and Methods of Instruction, } \\
\text { Language Acquisition, Turkish }\end{array}$ & $\begin{array}{c}\text { Instructional Technology and Materials Design, } \\
\text { Special Teaching Methods I }\end{array}$ \\
\hline & Special Teaching Methods II, Teaching & Teaching English to Young Learners II, \\
\hline \multirow{3}{*}{$3^{\text {rd }}$ year } & $\begin{array}{l}\text { Language Skills I, Teaching English to Young } \\
\text { Learners I, Methodology I, Literature and }\end{array}$ & $\begin{array}{l}\text { Teaching Language Skills II, Literature and } \\
\text { Language Teaching II, Language and Society, }\end{array}$ \\
\hline & Language Teaching I, Classroom Management & $\begin{array}{c}\text { Methodology II, Measurement and Evaluation, } \\
\text { Research Methods in ELT }\end{array}$ \\
\hline & Materials Development and Adaptation, School & Special Education, Teaching Practice, Turkish \\
\hline $4^{\text {th }}$ year & $\begin{array}{c}\text { Evaluation, Community Service, History I, an } \\
\text { elective module }\end{array}$ & ELT, History II, an elective module \\
\hline
\end{tabular}

\section{Appendix B}

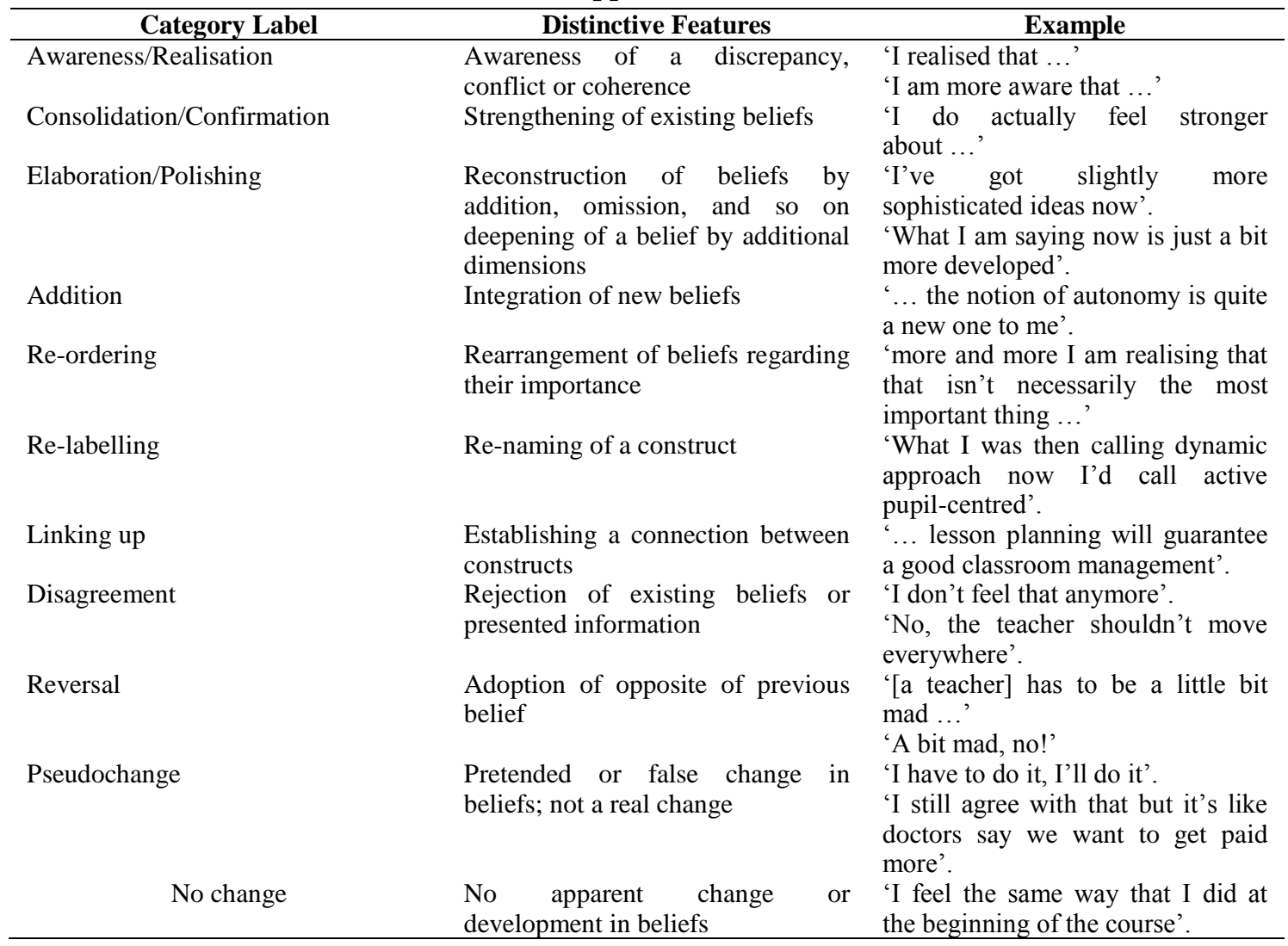

(Adapted from Cabaroglu and Roberts, 2000 p. 395) 